\title{
Eliot: El Poeta
}

\author{
"Wahrheit und Dichtung". \\ "Verdad \& Poesía". \\ (Autobiografía de Goethe). \\ SU POESIA HASTA 1925, la cué pŨede llamarse la poesía \\ árida de Eiliot \\ La paiabra inglesa JUVESCENCE viene del verbo latino JUVENES- \\ CO, que quiere decir llegar a ser joven. Su equivalente español sería \\ 'remozar". Entonses lahinea idelpoenadGERONTION. \\ "...In the juvescence of the year

\section{"Jorge Puccinelli Converso"} \\ Came Christ the tiger",
}

puede traducirse así:

"... En el remozamiento del año

Vino Cristo el tigre".

En estas líneas, se halla la esencia de la poesía seca de Eliot. Estos son los pensamientos de un viejo, y tiene (como mucho de la poesía de Eliot) un simbolismo doble. Primero, uno ve que Cristo nació, éfectivamente, el 25 de diciembre; es decir, en el hemisferio norte, pocos díás después del día más corto del año. El año está remozándose. Esta fecha no tiene importancia solamente dentro de la cristiandad, sino también en muchos ritos paganos. (Sería interesante notar que todas las fechas importantes de la cristiandad itenen más simbolismo en el norte que on sur). Tambión. cuando uno 
es viejo, llega siempre Cristo, que le hace recordar la vida gastada, la vida perdida. La vitalidad de la juventud mezclada con los pensamientos tardíos sobre la religión; una combinación de la cual sale la idea del Salvador como bestia feroz, pidiendo más de lo que uno tiene para dar, por no saber que puede ser dado.

La poesía seca de Eliot es la que lo hizo famoso. El mundo inglés de la post-guerra (1918-1925) encontró en él una amargura que correspondió al sentimiento general. Para entenderlo así, es necesario comprender el efecto de la guerra de 1914-1918 en la mente inteleutual europe: de aquella época. Fué la guerra más grande hasta entonces, y pese a su grandeza no fué una guerra de conquista ni religiosa. Las raíces económicâs fueron entendidas sólo por los economistas. La propaganda ideológica fué patentemente dirigida a idiotas. Podemos considerar la primera batalla del Marne. En esta batalla los alemanes trataban de pasar y los franceses no los dejaron pasar. Los franceses ganaron en el sentido de que cumplieron lo que se proponan, es decir, que no pasaron los alemanes; pero Alemanía dejó más de cuatrocientos mil muertos en el campo de batalla y millares do franceses se volvieron locos al ver hectáreas de tierra cubiertas de cadáveres. ¿Y cuál fué el resultado fina] de cuatro años de guerra lan terrible, jamás vista hasta entonces en el mundo? ¿Cuál fué el resultado? Nada, absolutamente nada. Sufrimiento, enfermedades; esd. Cíle ¿Perblquién stumo? Sufrieron los aliados tanto como los (dtemanes. Entohicesolarmente intelectual ouropea pensó que se había sido un baño de sangre completamente inútil, aun sin gloria siquiera.

Pensamientos de esta clase destruyeron la fé en los ideales de patria, de honor y aun de Dios. Y produjeron esa filosofía que podemos llamarla de entre-guerras: una especie de cinismo, sin fe. Este pensamiənto entre - guerras tuvo varias fases, principalmente, tres: 1.un relajamiento de la moralidad, una falta de respeto para las prohibiciones sociales y morales que habían existido; ésto se notaba sobro tocio entre las clases de poca culturo y era su manera de rechazar lo vie:o; 2.-.- una búsqueda de una fe nueva dentro del comunismo, bajo el escudo de la nueva dialéctica marxista de Moscúi y, 3.- una nueva literatura.

Las dos fases primeras no caben en esta tesis. Es la tercera que nos interesa. La nueva literatura se compuso de dos corrientes: a) hacia una reforma social, $y$ b) el rechazo de todo, una duda, un cínico desdén de cuanto existía. 
En esta segunda corrienie iiteraria se produjo la buena literatura de la época, y en ella se encuentran los grandes nombres de la literatura entre-guerras. Los escritores y poetas jóvenes de dicha época que buscaban una manera artística de rechezar se encontraban con Eliot en los años 1918-1925, y lo tomaban como líder y como símbolo del rechazo que ellos estaban buscando, y fueron ellos los que reconocían primeramente a Eliot, ellos los que lo hicieron famoso y le daban el nombre de primer poeta de la época.

Por eso es que Eliot es generalmente considerado como representante de la literatura cínica o rechazadora, y en sus poemas hasta 1925, este juicio tenía mucha razón. "The Waste Land" fué publicado en 1922, y es la cima de lo que llamo su etapa seca, pero es justamente en la cimá que abrió la puerta a su segunda etapa. En las líneas finales del Waste Land hay las indícáciones de una esperanza. En esta esperanza vemos la diferencia entre la primera y la segunda etapa.

En rnuy pocas palabras, los primeros poemas de Eliot, dicen que lo que hay no sirve: no hay nada importante; estamos viviendo en una tierra yerma, y rosotros somos hombros huecos que no sabemos porqué existimos. La segunda etapa sigue diciendo que no hay esperanza, pero el mensaje es que el hombre tiene que rendirse a la desesperanza, camino que conduce a la salvación. quiere decir, una fe tan absoluta que no necesita ni esperanza.

Entre sus primeros poemas, los más importantes en mi opinión son

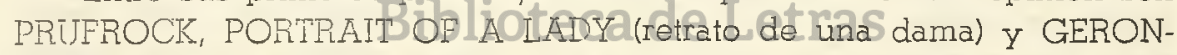
TION. "Jorge Puccinelli Converso"

Un problema sobre la obra de Eliot que no se resolverá fácilmente es si el cambio entre su poesía seca y su poesía de fe es realmente un cambio o nada más que un paso en su desarrollo. Uno que lea "The Waste Land" $\sin$ leer "Ash Wednesday" no se daría cuenta de las posibilidades de poesía religiosa que tiene el poeta; no obstante, después de leer "Ash Wendnesday" sería fácil fijarse en que "The Waste Land" fué un paso necesario para la revelación del poeta completo. También uno puede pensar que el poeta completo aun no ha sido revelado, $y$ que, como Dante, necesitaría tres etapas: infiemo, purgatorio y paraíso. Por cierto, Eliot todavía no ha salido del purgatorio. Hay personas que dicen "ique salga y que se vaya al cielo de una vez!"; pero me parece interesante tener la oportunidad de asistir al desarrollo de una personalidad que ha tenido y tendrá un efecto tan grande como Eliot.

Este pensamiento nos lleva a considerar de que elementos se compone exactamente la influencia de Eliot. Podemos dividirla en dos par- 
tes: 1) efectos literarios, y 2) como líder o síntoma del pensamiento moderno.

Efectos literarios. - Ha sido uno de los poetas principales en el rechazo de las formas acostumbradas de la poesía, como rimo y metro. Ha usado símbolos e imágenes basadas en símbolos. Estas mismas corrientes se notan en todas las demás formas de arte, como la novela, la pintura, la escultura, la música, etcétera. Tienen varios nombres, como surrealismo, modernismo, impresionismo, música pura y otras. Es temprano juzgar el valor general de la nueva moda, pero personas que mandan todas las corrientes nuevas al diablo sin estudiarlas bien, hacen mal. Un error común es ver una muestra del arie nuevo (que efectivamente no es tan nuevo como creen) y decir: "No me gusta, y si ésto es lo nuevo, no me gusta lo nuevo". Hay que recordar que en todo arte, un alto porcentaje de lo que sê produce es mediocre o malo. Por un Cervantes había por cierto, una gran cantidad de escritores que vivín en la misma España en esa mismápoca y desde hace tiempo han sido ya olvidados. Quien quiera juzgar la nueva moda tiene, pues, que juzgar los elementos representativos. En la pintura no sería justo examinar un cuadro de Fulano de Tal y condenar igualmente a Picasso o a Matisse. La importancia literaria de Eliot es que él ha sido ya considerado el representante de la poesía nueva. Tal vez los siglos rechazarán estéljüpiot RRO TEM Tyeéscogerán otro, pero, entre tanto, hay que tomar en cuenta que casi toda la opinión literaria inglesa de Europa y América considera a Eliot como lo mejor que hay entre los poetas de la moda contemporánea. Quien quiera que la atacan, atacan a Eliot; los que la alaban, alaban a Elliot, y si hacen comparaciones entre poetas contemporáneos, tienen que emplear a Eliot como medida.

Cualquiera puede decir que no le gusto esta corriente poética nueva, pero no debe decirlo sin leer a Eliot. He aquí la importancia literaria de Eliot.

No debemos olvidar la importancia artística de Eliot: es decir, la romunión casi sagrada que pasa entre el poeta (o pintor o músico o escritor) y el espectador o lector. El poeta, como dije antes, presenta, a través de su propio sentimiento, la esencia de alguna cosa, persona, sitio, cultura o edad. El lector la recibe o nó: esta es una comunión personal. Si bastantes lectores la sienten, se dirá que el poeta es genial. Al parecer, Eliot logró tener esta comunión, aunque, por la dificultad de leerlo, tiene todavía una audiencia limitada. 
¿Líder o síntoma? Esta cuestión no cabe completamente en la seccićn sobre la poesía seca de Eliot ni en la de su poesía de fe, sino en las dos, pero la consideramos en ésta.

Un problema fundamental de la siciología es el de determinar si los líderes guían la sociedad o si la sociedad crea los líderes cuando los necesita. Por ejempło, ¿fué Hițer quien guiaba la cultura alemana o fué Alemania que crés un líder cualquiera como símbolo de los impulsos sociaies? En otras palabraş, ¿era Hitler figura o fuerza matriz? Este probiema tiene aspectos de la pregunta clásica, ¿cuál vino primero, la gallina o el huevo?

Siendo aparentemente imposible resolver este problema, sin embargo, podemos tomar al líder (mientras tenga seguidores) como muestra de la voluniad general, dejando de lado la cuestión de prioridad. No imporia, pues, si Eliot guía o ha surgido como expresión de la mente común. Puesto que es líder, es evidente que servirá como ejemplo para el estudio del pensameinto moderno.

Eliot como guía del pensamiento moderno-- Es generalmente imposibie en esia época distinguir entro las varias corrientes sociales. Ia política no se ve separada de la economía. Los cambios sociales cuentan con raíces históricas, políticas, económicas y personales. En la escena grande de la cultura occidental (que muchos creen que se encuentra actualmente en las primeras etapas de su decadencia) hay varias fuerzas que operan, sea idomio dausa o defectoetras

Entre ellas hay las siguientes: inemi Ed disminuir de la religión de Cristo como fuerza motriz. Esta comenzo con el renacimiento y ha seguido hasta hoy on que las palabras de Cristo tienen un efecto casi nulo en la vida diaria, como el poder temporal de las iglesias; 2. - La tradición en un estado decadente. Cada día vemos con mayor claridad que es necesario reemplazar la tradición con las fuerzas armadas. Mas que nunca se ven revoluciones, motines, tumultos, suprimidos no por el prestigio del gobierno o la tradición, sino por la fuerza. Las condiciones económicas o políticas que las causan no son mayores que antes, pero la época está inquieta. Una escasez de pan, por ejemplo, en una época tranquila, sería aceptada como cosa inevitable. Ahora solamente el ejército sería capaz de contenerla. Como va el ejército, así irá el gobierno. Un ejército débil casi siempre ocasiona una revolución; si tiene éxito la revolución, el primer paso del nuevo gobierno es hacer fuerte y más leal al ejército. Hemos visto tales fenómenos en Alemani, Rusia, España y los países latinoamericanos. Si tuviera poder la tradición, no se realizaría así. 3.-El desarrollo de la ciencia fuera del 
entender el hombre. Si viniera un indio del campo a Lima, se hallaría asustado con los adelantos técnicos que encontrase. Esto ya es cosa natural, pero no sería natural encontrarse con un limeño incapaz de trătar y eniender su propio ambiente; pero así es. El alemán (como nativo de la civilización que ha desarrollado más la técnica) jamás imaginaba ni pudo gobernar las fuerzas mecánicas que lo lievaron hacia la guerra. Aun ahora se encuentra el alemán explicando que la guerra no fué culpa suya: no entiende que la misma técnica que él había perfeccionado llegó a seri su maestro en vez de ser su servidor. Actualmente en los Estados Unidos, que hoy porta la bandera de la técnica hallamos que cada año mueren más de cuarenta mil perosnas en accidenies de automóviles, quiere decir que el norteamericano, por mecánico que sea, aun no ha logrado dominar al auto. ¿Quién, entonces, domina el avión y la bomba atómica?

Otro aspecto del mismo problena es que el perfeccionamiento de los métocios de producción ha privado al hombre de la satisfacción de hacer un trabajo completo. Antes, todas las sillas fueron hechas por carpinteros, haciendo cada carpintero el trabajo total. Ahora, en los Estados Unidos, por ejemplo, la mayoría de las sillas están fabricadas parte por parte, con maquinaria automática, y los obreros nunca tienen la satisfacción de ver algo hecho por ellos mismos.

La difusión de la tecnología no se contendrá fácilmente. Muestra de esta dificultad existejen el casa deelós paísess dentro de la cultura española. Los intelectuales represeniantes de dicha cultura siempre han trataco de desprestigiar la tecnofogia, pero nunca han sido capaces de pararla, ejemplo de lo que puede verse actualmente en Lima.

4.- La dialéctica marxisia (o stalinista), que es nada más que una búsqueda de un camino para el hombre como servidor de la máquina, pudiendo considerarse imposible que logre dominarla.

He dicho esta digresión para hacer más clara la posición de Eliot. Lástima que una exposición completa de estás ideas -- las cuales han sido presentadas tan arbitrariamente - no cabe dentro de la presente tesis, aunque ojalá basie como base de una explicación de Eliot como guía del pensamiento moderno.

Eliot, en su primer paso (su obra hasta 1925) está tratando de presentar al hombre bajo estas fuerzas, a saber, la decadencia de la cristiandad, el reemplazo de la tradición por la fuerza armada, el desarrollo enorme de la tecnología y la presión de la dialéctica stalinista. Sería equivocación decir que Eliot está hablando solamente sobre el hombre 
de hoy; él está halbando sobre todo hombre en todo tiempo, el quien carga más de lo que puede. Pero el ejemplo que Eliot usa y el valor que para nosotros tiene, es la situación presente

Si pensamos en el hombre como una cosa débil, pero sin embargo una cosa que lleva en sí posibilidades enormes, y luego pensamos en la pequeñez de los problemas actuales del hombre frente a sus posibilidades, vemos que la humanidad es como una tierra yerma donde debe crecer óptimos frutos, pero donde no crece nada. He aquí la esencia de la poesía seca de Eliot.

Los símbolos que usa para demostrar ésto se verán en el análisis del "Waste Land", que es el poema culminante de su etapa seca, y lo que mejor muestra dicho sentimiento.

El éxito que han tenido los poemas de la etapa seca (sobre todo THE WASTE LAND) es lo que le da a la obra de Eliot una importancia como guía del pensamiento moderno, porque si fuese una voz fuera de la corriente del tiempo, nadie la escuchría; pero desde el momento que comenzó a escribir parece que ha expresado un sentimiento casi universal. Por la dificultad de su poesía tenía relativamente pocos lectores, pero entre los que sí lo leían se hallan casi todos los pensadores, críticos y líderes del mundo occidental. Otros escritores han producido una literatura que, siendo más simple, ha alcanzado una audiencia más grande. Esta literatura, expresando el mismo tema que Eliot, es actualmente la literautra representativa de la inglesa. Podemos nombrar a John Dos Passos, James T. Farrel, Ernest Hemingway, John Steinbeck, Aldous Huxley, Jamed qbžce, Evelyn Waughyemuchos otros más. En interesante notar que todos estos comenzaron, como Eliot hablando solamente sobre la tierra yerma: el contraste entre la potencialidad del hombre y su actualidad. Casi todos, más tarde, iban buscando algo más allá de la esterilidad: iban buscando una esperanza.

Es aquí que los comunistas dejaban a Eliot y a los demás, porque los comuristas que habían estado de acuerdo con la tierra yerma, no están de acuerdo con la idea de Eliot de encontrar la realización de las potencialidades del hombre dentro del hombre mismo, sino que la buscan fuera del hombre, en la organización social y en la tecnología. (Quiero decir, como digresión, que lo que yo diga en contra de los comunistas, no debe ser considerado como defensa del capitalismo en sí, porque el capitalismo en la forma como está desarrollándose no es muy diferente al stalinismo; es, en realidad, otro tratamiento, para hacer al hombre servidor feliz de la máquina. Además, el capitalismo ya no existe sino como sistema protegido por el estado, y en todo el mun- 
do va transformándose en una especie de socialismo. La dialéctica stalinista no está pues, muriendo, sino naciendo; es más importante, porque es algo diferente). El comunismo, entonces, no puede soportar el concepto de la individualidad, y Eliot nunca abandona al individuo.

Me parece que el individuo, sin religión y sin tradición, esforzado por las corrientes de una teconología demasiado desarrollada y una dialéctica que trata de ponerlo como servidor de la máquina, se siente inquieto, preocupdo, perdido e infeliz.

Me parece que Eliot en sus poemas secos, ha expresado esta inquietud, preocupación del hombre; la ha captado y expresado en su esencia; - no sólo del hombre de hoy, sino del hombre de todo tiempo. Por el hecho de expresarla, Eliot ha llenado la primera misión del poeta.

Su manera y método de expresarlo, que son los aspectos artísticos, serán considerados en el análisis de "The Waste Land". Lo importante es que Eliot, expresando esta inquietud entre las guerras, ha logrado la expresión de la edad aunque su intención fuera todavía más grande. Estoy seguro que Eliot no intentaba expresar solamente la angustia de la generación entre-guerras, pero fué esto lo que lo hizo famoso.

Lo valioso en estos poemas secos no está en la expresión de algo de un cierto tiempo, sino es la voz del hombre de culquier tiempo que vive sin Dios y sin tradición, en un sistema que no entiende. Este es el hombre en la tierra vermalethombre que hatrolvidado los símbolos. ¿Qué debería hacer éste? geiDóndenval Ellot? veEnosu última parte del WASTE LAND y en ASH WEDNESDAY, como vemos en la siguiente sección, hay un segundo paso de su poesía.

\section{SU POESIA DESPUES DE 1925, que representa una actitud de esperanza en la fé y en la tradición.}

Me parece que su poesía, después de 1925, vale menos que la de la etapa anterior, porque en ella ya no expresa un sentimiento universal, sino sus propias ideas. Eliot mismo es tradicionalista, monarquista y cristiano; en su pcesía devocional pide un retorno a una fe absoluta, o si no lo pide, dice que él está tratando de alcanzarla. Los pensamientos propios de Eliot pueden ser bien interesantes pero para mi no alcanzan la misión más importante de la poesía, que es, como dije antes, la expresión del sentimiento o esencia de la humanidad en forma poé- 
tica. También me parece que la poesía en sí no es tan buena como la de antes. Las imágenes me parecen à veces un poco forzadas. Finalmente, yo todavía no he sentido una disposición general de retornar a la fe absoluta.

Sin embargo, me doy cuenta de que casi todos los que comenzaron pensando en la esterilidad de la vida humana llegaron al fin a retornar a la fe o a creer en la organización social, la cual es en sí un cierto tipo de $\mathrm{fe}_{\mathrm{e}}$ un reemplazo de Dios por una máquina. Entonces, es muy posible que Eliot sea precursor de una nueva edad media de fe absoluta, y que yo, por ser joven, todavía no he alcanzado a verla. A pesar de ésto, creo que la única salida de la tierra yerma está en el individuo, y que cada individuo necesita lograr descubrir su propia fe, la cual no existe sino dentro del ser huamno mismo. No veo como la tradición y una fe hereditaria pueden substituír la fe personal, y no estoy de acuerdo con Eliot en tanto que él quiere una tradición o fe que impediría al individuo buscar su propia tradición o fe.

También tenemos que recordar que su poesía después de 1925 no pretende ser más ni menos que poesía, religiosa o devocional, y, por lo tanto, no hay derecho a criticarla como otra cosa. La medida de universalidad no sirve para la poesía religiosa, porque la religión tiene que ser cosa personal. No debemos criticar la fe de uno, pero cuando uno escribe sus ideas religiosas en la forma de poesía, quiere decir que desea que otros la lean. Desde este punto de vista, y en comparación con otras poesías religiosas quae hacroducido da cristiandad (como las de San Iuan de la Cruz y John Ponne, por ejemplo) me parece que Eliat todavía no ha escrito, en el campo de la poesia religiosa, poemas tan buenos como los que ha producido en el campo de la poesía no religiosa.

Creo que Eliot cayó en el mismo error que tantos otros: el error de tratar de mejorar la Biblia. Recuerdo que Thomas Mann escribió tres libros sobre José en Egipto, los que he leído. Después leí las cuarenta y pico líneas sobre el mismo tema en Biblia, las que me parecieron más claras, más artísticas y más espirituales que las setecientas páginas que empleaba Mann para decir la misma cosa. En ASH WEDNESDAY los mismos pensamientos, las mismas imágenes, hasta las mismas palabras son prestadas de la Biblia y de San Juan de la Cruz. No hay espacio para reproducir estas fuentes aquí, pero el lector interesado puede leer el Eclesiastés y Ezequiel de la Biblia y La Noche Oscura del Espíritu de San Juan. No hago esta crítica para decir que Eliot hizo plagios, sino para decir que la expresión de su fe o su intento de alcanzar 
una fe es más bien un sermón o un ensayo que poseía a nivel de su obra anterior.

Lo bueno para mí en su poesía religiosa es que, fundamentalmente, Eliot está diciendo siempre que la fe es particular. No habla de una cosa generalizada. Cada lector tiene que sentir hasta qué punto Eliot cree en una fe particular, hasta qué punto en la tradición.

Parece que Eliot ha dicho todo lo que puede decirse sobre la tierra yerma, y ahora está probando decir algo más, de ir desde la futilidad a algo más allá. Desde 1925, ha escrito solamente dos poemas, ASH WEDNESDAY y FOUR QUARTETS (que en realidad son cuatro poemas), y tengo la idea que, de ninguna manera, su obra haya concluído. Por consiguiente espero que aun veremos una expresión completa de sus ideas de tradición.

En la última parte del WASTE LAND, el trueno dice: "idad! jcompadeced! ¡gobernad!". En estas tres acciones se halla, tal vez, la filosofía de Eliot, y el signifcado de sus ideas de tradición, y creo que la próxima etapa de su poesía será un desarrollo más amplio de estas ideas. Tengo la idea que lo que dirá Eliot, es que el secreto de la felicidad en la vida es una tradición que da, compadece y gobierna. El secreto de la salvación espiritual está en rendirse absolutamente y sin esperanza a Dios, y que estosi dos secretos van ayudándose uno al otro. La mejor manera de alcanzar a Dios o la rendición absoluta es vivir en una tradición. La tradición y la rendición a ella son símbolos de la rendición final a Dios, yoquecpor haber perdido la tradición simbólica estamos viviendo en una tierra yerma. La poesía religiosa de Eliot me parece que quiere decir que es posible, aun en la tierra yerma, rendirse a Dios. Por su propia cuenta, Eliot ha hecho todo lo posible para vivir bajo una tradición actual. Como el caballero en la leyenda, Eliot está tratando de restablecer el valor perdido de los símbolos tradicionales, para hacer posible la rendición absoluta. En el poder de rendirse absolutamente, según Eliot, está lo santo del alma humana.

Norman D. Arbaiza. 